\title{
Application of Mobile Technology in Activity Design
}

\author{
Ousimani Zhang \\ College of Literature \& Law, Tianjin Open University, \\ No.1 Yingshui RD. Nankai Dist. Tianjin, 300191, China \\ email: osmnzhang@126.com
}

\begin{abstract}
The M-learning activity designs play the very important role in the M-learning which determine and ensure the learning effects. This paper analyzes the M-learning concept and characteristics based on sorting out the existing definitions. Besides, the M-learning activity design framework is presented, expounding the four factors, demand analysis, key factors, core factors and evaluation design.
\end{abstract}

Keywords: Mobile Learning; Activity Design Framework; Theory of Activity

\section{Introduction}

With the development of modern mobile communication technology, whose implication is growing and system development of Bluetooth, WAP, GPRS, mobile phones and Mobile PCs are rapidly spread all over the world, which provide the technical basis and material prepared for Mobile learning(M-learning), which is a new learning mode in education.

M-learning, breaking traditional classroom teaching mode, allows the learners develop the individual learning in terms of personal preferences and needs and free them from the limitation of time and space, achieve the learning wherever and whenever possible. M-learning effectively strengthen communication and interaction between the learner and instructor, among the learners during the leaning process, which is the lack of prior e-learning. ( Rekkedal\& Dye, 2007 ) It's the key factor for the success of M-learning how to ensure the effectives of learning in the informal learning environments and fragments time. Some experts agree that M-learning is seemed as the learning activities which transmit learning resources through mobile terminals. So focus on the learning process and effectives, we must think highly of the learning activities design. This paper is going to analyze the definition, characteristic and activity design framework of M-learning through the theory of activity perspective.

\section{Concept of M-learning}

At present the definitions of M-learning are mostly descriptive, no 
authoritative and accurate. Only many academics define the concept from the different angle, which include the followings.

1. Based on the technology. M-learning is the learning with the mobile devices, emphasizing the technical characteristics, which is the prevailing view. The more representative one is that M-learning is the combination of mobile computer and digital learning, including anywhere or anytime leaning resources, powerful search ability, rich interaction, and strong support for effective learning and based performance evaluation. (Clack Quinn, 2007)

2. Based on the e-learning comparative definition. It thinks it as the extension of e-learning, focusing on the relationship between them, such as that M-learning is the new stage in development of distance learning and digital learning. ( Georgiev, 2004)

3. Based on the activity. In this view, the activities of teaching and learning could transmit by mobile device. This paper will be in accordance with the view.

\section{The characteristics of M-learning}

M-learning, a new digital learning mode, has typical characteristics differ from the others.

1. Mobility. It's a basic characteristic. With the development of technology, mobile terminal devices are diversified and portability, with which learners could free to get the learning resources they need any where and anytime, without the limitation of fixed teaching place and wire line networks connection.

2. Personality. Learners, decide their own learning style, content, paced in terms of the preference, could study by themselves or group, access to lots of learning resources, and engage in practical operation. They could choose learning tools suitable to them.

3. Micromation. Micro learning makes knowledge to decompose little blocks which to be suitable for learning in fragment time without outside interference. From the media, micro content could be small text, figure, audio and video, flash or a link and so on.

4. Interactivity. The key characteristic of mobile devices is interactive, by which learners could make a communication with instructors to solve the problems, other learners at different ages to exchange information.

\section{Mobile learning activities design based on theory of activity}

\section{The theory of activity}

The philosophical grounding for the M-learning is the philosophy of dialectical materialism, Engels Marx, which is the descriptive theory of various activities, analyzing the activities existing in human society, whose basic research content is a two-way interactive process of man and natural, social environment. Human activity system has 6 elements, including subject, object, community, tools, rule, and division of labor, which are inactive and influence the design of learning activities. 
On the constitute elements of activity system, the activities of M-learning consist of the following elements, learning subject, learning object, learning community, learning tools, interactive rules, learning division. For designing the M-learning activities based on the theory of activity, it is very important to analyze the relation among elements from global perspective in order to make the learning activities with optimization and design achievements with operation.

1. Learning subject. As the learning subject, learners play the main role in the activities. Due to the different learning style and characteristics, we should analyze the learners to design the learning resources meeting the needs what they are looking for, arousing their learning motivation.

2. Learning object. It refers to learning contents in the M-learning, for example, learning target, learning resources and learning task.

3. Learning tools. Tools, as the essential factors, refer to environment and conditions in the learning activities, such as mobile terminal devices, learning tools and learning methods, in which the mobile technology plays the important role to change the learners' learning mode.

4. Interactive rules. In the M-learning, the rules, made by subject and learning community, run through the whole learning activities to guide the learning activities and governing the learning behavior.

5. Learning community. It refers to the others participants who achieve the learning tasks with subject in the M-learning, including instructors and learners. During the learning process, community provides the resources they need and advice with learners, influencing the subject's knowledge-construction.

6. Learning division. It refers the task-dividing in the learning activities among the learners. Different learners need to play their own advantages to fulfill the individual task in a specific activity. Although during the learning process, learners have to change their role, each learner must accomplish their task supposed to perform in any event.

\section{M-learning activity design framework}

Through drawing the teaching design methods, based on the theory of activity, we construct M-learning activity design framework, (Figure1.) which is consisted by demand analysis, core factors analysis, key factors analysis( tools design, context design, rules design and division design) and evaluation design. The following is the details.

Demand analysis

Through the demand analysis, the first one is to confirm the learning contents suitable for M-learning. The second one is to analyze learner's learning ability, whether they have mastered required knowledge, which is benefit for arranging the learning contents. The last one is inform the learning target, teaching task, interactive process and technical requirements. 


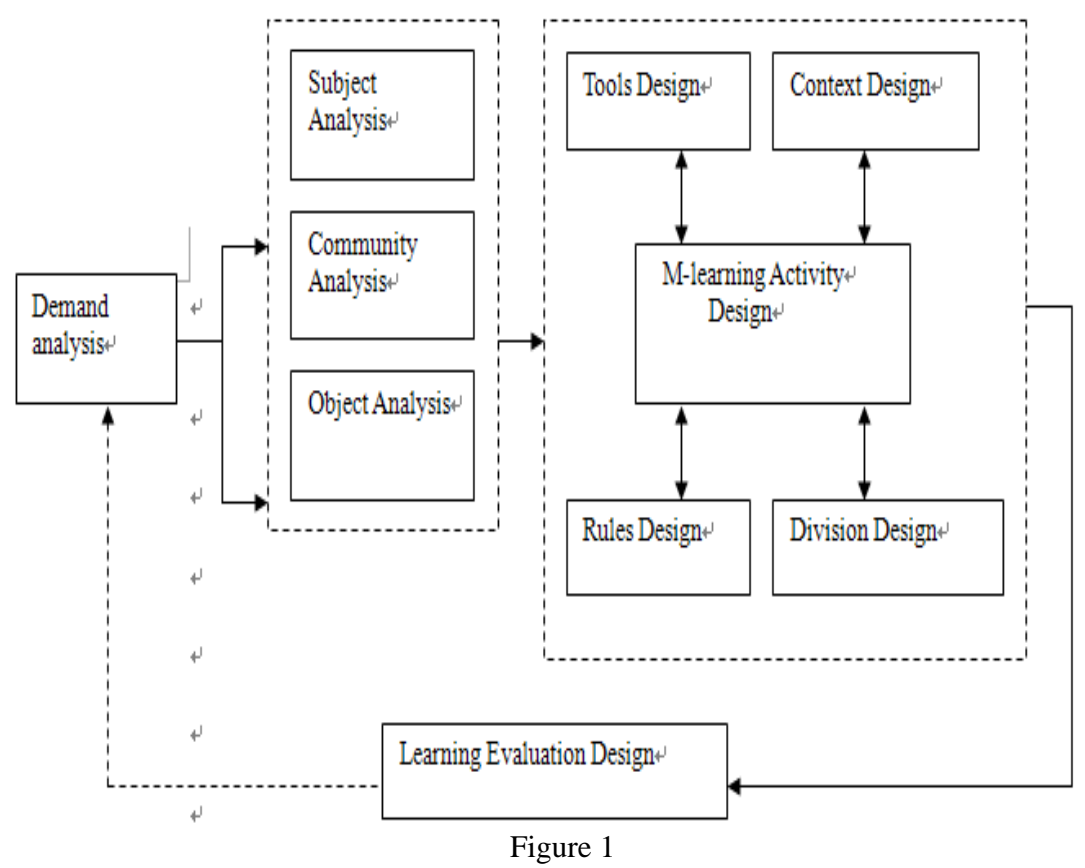

\section{Core factors analysis}

As the subject in learning activity, learners' basic characteristics, such as age, learning motivation, style, required knowledge and experiences, technology ability need to be known about. Besides, M-learning is going under the state of motion, we also especially grasp the learner's needs, control their attention, motivate learners' readiness to learn and learning engagement.

Object could be thought as learning target, task or content in the M-learning. As a informal learning, M-learning target should show its practicability, knowing about different learning targets to help to design learning task with interesting and meeting needs. Learning contents could be the little knowledge blocks, such as short text, image or video, which are short and completed in principle.

Learning community, instructors and learners, is built through interactive activities among the learners based on the mobile network. M-learning modes are fruitful, individual study and group study.

\section{Key factors analysis}

In the M-learning activities design, a large learning activity could be divided into a series of individual sub-micro activities, which are completed by learners, instructors and partners together. Learning tools are the requirements in the 
learning activities, including communication network, mobile terminal devices and learning portal, which provides some tools, such as media communication, cognitive tools, information resources, evaluation tools and learning consulting, to cultivate learners' ability of thinking. During designing learning activities, the tools could be fully analyzed in terms of learning target and needs. Rules are related regulations and standards to regulate learning behavior, which are the necessary conditions to ensure learning activities in orderly manner. For completing the learning tasks, teaching designers should design the rewards and punishment rules, completion rules and evaluation rules, resolving conflicts and cooperation rules to constraint learning behaviors. If the group study, learning activities must clearly defined responsibility and task. So designers need to consider how many roles and what experiences to be need in the learning activity, according to which, organize rational division to encourage each learner to participate learning activity actively. Furthermore, designers try to combine the real common life and society activities with learning tasks, which could make learners to achieve learning task or resolve problems based on the real situation by the usage of mobile terminal devices. Learning context and activities design worked closely. Significantly, different learning activities are supported by different learning contexts.

\section{Learning evaluation design}

The feedback of learners' study is obtained by evaluation of learning activity, which could make the design process to perfect and improvement. The design framework features diversity on evaluation methods, dimension and criteria, both quantitative and qualitative evaluation, instructors and learners-self evaluation, summarized evaluation on learning activities and formative evaluation on learning process. In the M-learning, its feedback and evaluation could be done by quiz and vote and so on, which are with micro characteristics.

\section{References}

[1]Sharpies, M. The Design of Personal Mobile Technologies for Lifelong Learning[J]. Computers and Education, 2000, 34: 177-193.

[2] Jonassen DH.Murphy L R. Activity theory as a framework for designing constructivist learning environment [J].Educational Technology, Research and

Development, 1999, 47(1):61-80.

[3] Sharma, S., Kitchens, F. Web Services Architecture for M-Learning [J].Electronic Journal on e-Learning, 2004, 2（1）, 203 216.

[4] Mobile Learning Anytime Everywhere[DB/OL].http://www.mobilearn.org/mlearn2004.

[5] Kaenampornpan, M., O’Neill, E. Modeling Context: An Activity Theory Approach [J].LNCS, 2004, 3295:367 374. 